\title{
Incorporating computational fluid dynamics in the design/build of a single family residence
}

\author{
J. Chang \& N. Rosemann \\ School of Architecture and Urban Design, University of Kansas, USA
}

\begin{abstract}
This paper discusses the design, development, and construction of a single family residence approximately $112 \mathrm{~m}^{2}\left(1200 \mathrm{ft}^{2}\right)$ in size that was designed and constructed by a team of graduate and undergraduate architecture students within a single semester. The project involved the implementation of computational fluid dynamics (CFD) during the design development stage of the project to achieve appropriate mechanical distribution of conditioned air. The computer simulated analysis of the environment focused on the ventilation effectiveness and temperature distribution of the home's mechanical system. The paper also discusses the results of a comparative analysis of the simulated data and that of the experimental data taken of the building after the completion of construction prior to occupancy. The findings of this project provide insight into how CFD can be better incorporated into future studio design/build projects.

Keywords: design-build, design studio, computational fluid dynamics, prefabrication, modular design, computer simulation, temperature distribution, architectural education, residential architecture, environmental analysis.
\end{abstract}

\section{Introduction}

When it comes to design/build projects in architecture schools, more often than not the projects are executed with insufficient analysis of the design's environmental performance. This oversight can become more evident as the project increases in scope while maintaining the same time frame of one semester. As with any project dealing with the built environment, attention should be given to its environmental performance to better provide occupants a healthy, effective, and efficient environment. 
One means of increasing the ability to deliver an effective built environment is to conduct environmental performance analyses during the design development stage of a project. Using analysis tools such as computational fluid dynamics (CFD) software can provide performance feedback on a design within a short period of time. Such feedback can provide the design team with the necessary information to make appropriate design changes that help improve a project's environmental performance.

\section{Design process and design analysis}

At the University of Kansas School of Architecture and Urban Design, for the past eight years a group of about twenty graduate and undergraduate architecture students in Studio 804 have embarked on a semester long design/build project that takes them from design and construction to occupancy of a single family residence within about four months. Under the guidance of Professor Rockhill, the latest group of students designed and constructed modular3, a $112 \mathrm{~m}^{2}(1200$ $\mathrm{ft}^{2}$ ) single family prefabricated modular home for a Kansas City neighborhood. This project utilized CFD for part of the design development of the house.

Working with a very tight schedule, students had approximately four weeks at the start of the semester to design and complete construction documents of the house. This left about two weeks to work on the design during which time continuous analysis of the mechanical system was performed using a commercially available CFD package. Under the supervision of a CFD instructor the simulations were conducted by one of the studio's graduate student who had prior, albeit limited, experience with CFD. Although extensive analysis was conducted during the two weeks of design development investigating natural and mechanical distribution of air, a change in site location just prior to the scheduled construction date negated the design and CFD analysis of the original modular3, fig. 1 .

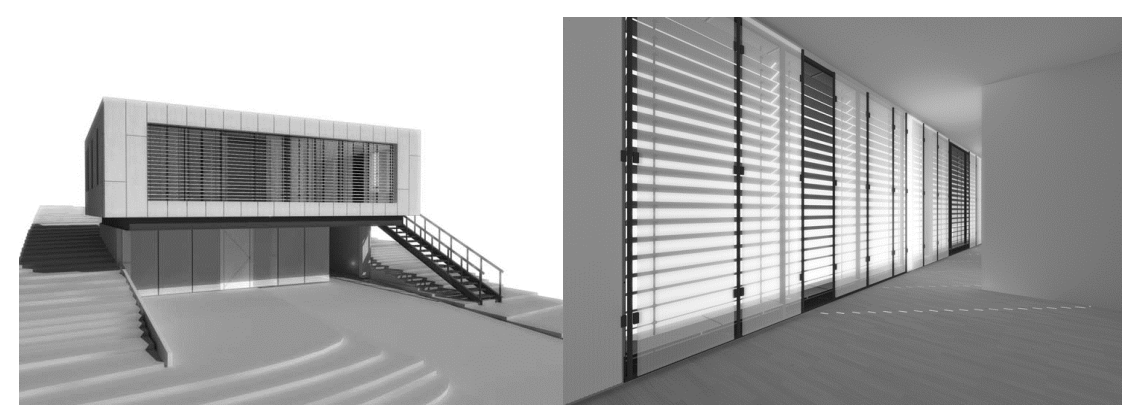

Figure 1: Exterior and interior computer renderings of original modular3 design. This design was discarded with a change in building site.

With a new building site in place, the original modular3 was completely redesigned within two weeks to meet the new site conditions and revised construction start date. The revised schedule allowed just a few days to run 
simulations and provide design feedback to the group. Although far from desirable, those few days provided beneficial information in regards to the layout of supply and return vents. Approximately ten weeks later construction was completed and modular3 was ready for occupancy, fig. 2, fig. 3, and fig. 4.

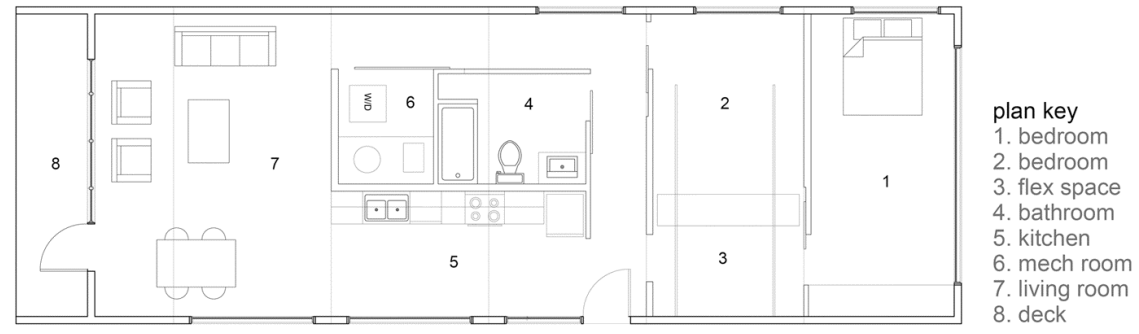

Figure 2: Floor plan of redesigned modular3 to fit new site conditions.
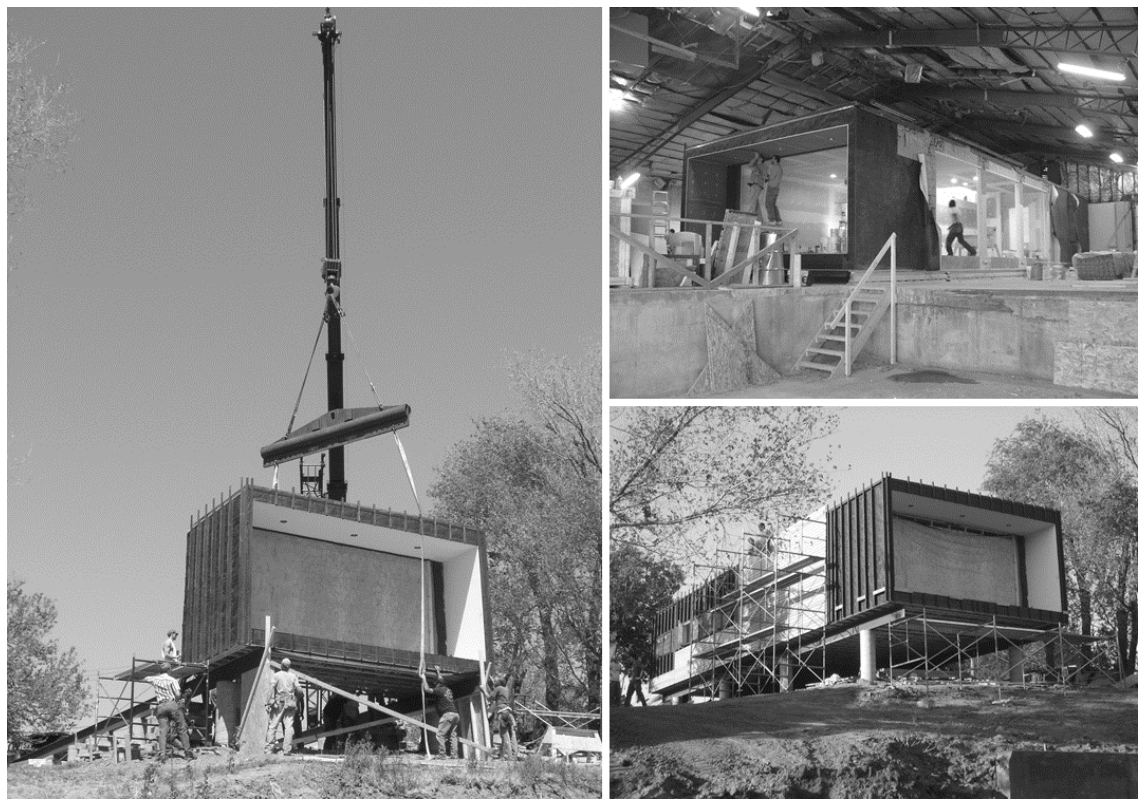

Figure 3: Images of redesigned modular3 under construction.

\subsection{Pre-construction analysis}

Given the very short time frame to redesign the house, simulations were started after the new design was fairly established. Although this limited the degree to which the CFD simulations could impact the overall design, it focused attention on the distribution and layout of the supply and return air vents.

The initial simulations revealed areas in need of improvement in terms of temperature distribution and local mean age of air (LMA). As shown in fig. 5, 
temperature difference between the living room and bedrooms varied by as much as $4.5^{\circ} \mathrm{C}\left(8^{\circ} \mathrm{F}\right)$. Uneven air circulation is illustrated in fig. 6 with particularly poor conditions in the bedrooms.

Based on these findings, several adjustments were made to improve airflow. Each bedroom received an additional supply vent and the living room and kitchen added a total of four additional supply vents. Furthermore, the return vent was divided in two and placed in two different locations, perpendicular to the original location. The modifications resulted in a more uniform temperature distribution as shown in fig. 7, with temperature differences varying by about $2.25^{\circ} \mathrm{C}\left(4^{\circ} \mathrm{F}\right)$. CFD simulation based on these changes also illustrate an improvement in airflow over the initial configuration of supply and return vents, fig. 8 .
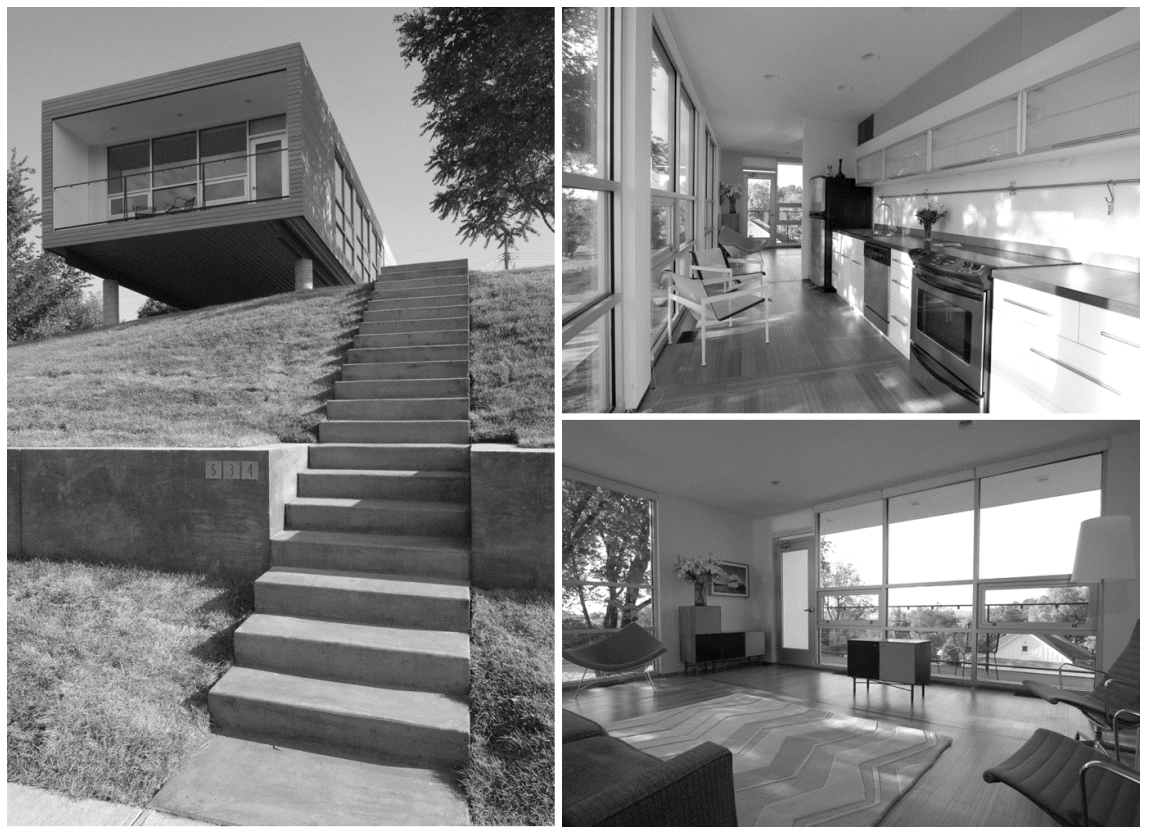

Figure 4: $\quad$ Finished exterior and interior images of redesigned modular3.
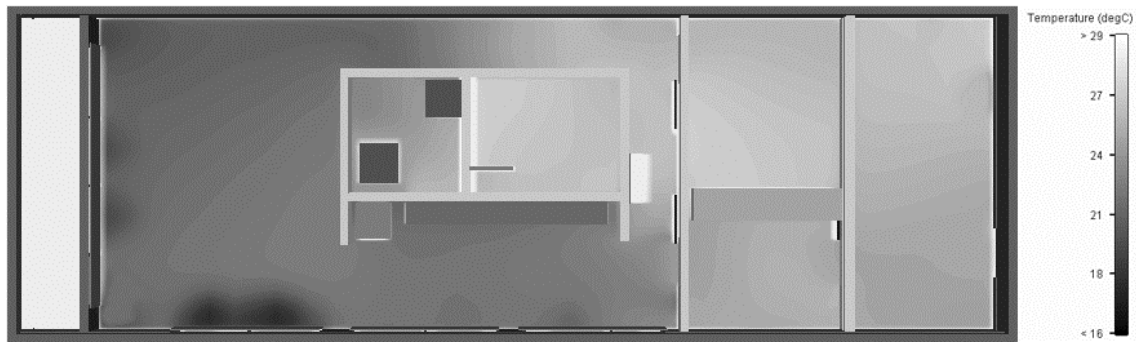

Figure 5: Temperature distribution of initial supply and return air vent configuration. 

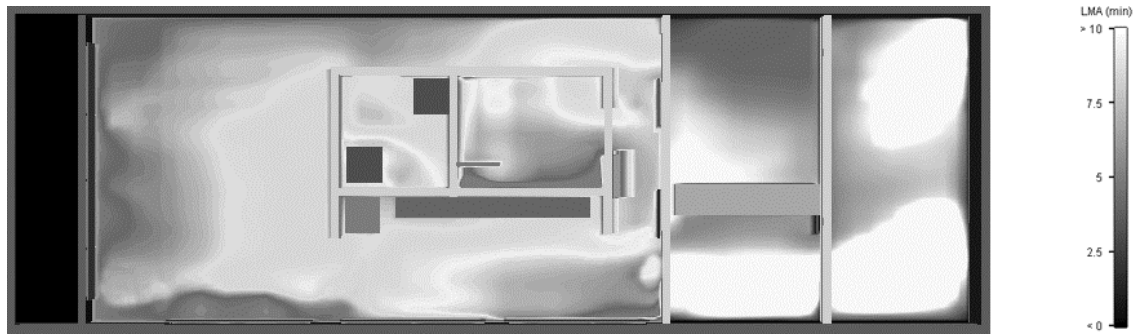

Figure 6: LMA distribution of initial supply and return air vent configuration.
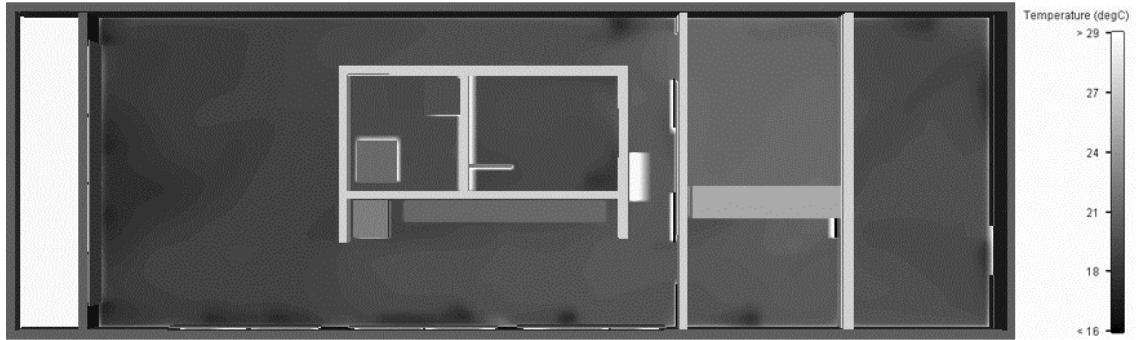

Figure 7: Temperature distribution of revised supply and return air vent configuration.
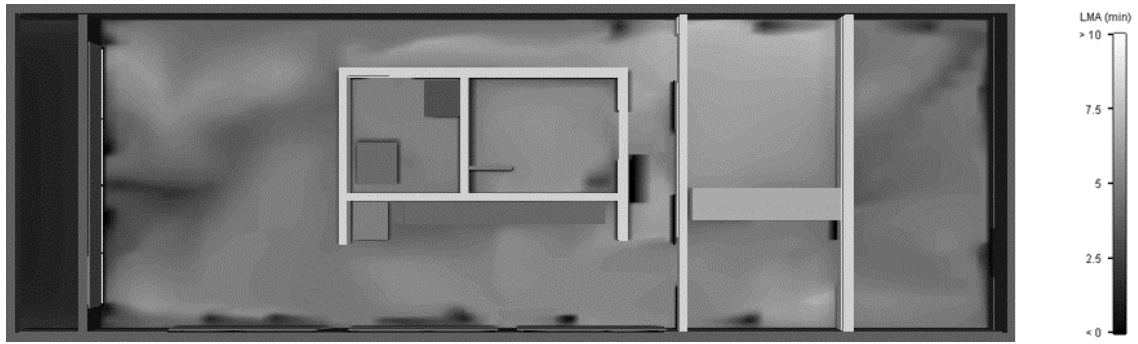

Figure 8: LMA distribution of revised supply and return air vent configuration.

\section{Results: comparing simulated and actual data}

After the completion of construction, air temperature and air velocity were measured at various locations in modular3 to compare the actual performance to simulated data. Once the actual performance data were collected, a new simulation was run based on those findings. Unfortunately, long term datalogging of environmental variables was not possible due to the house being occupied. The results from that simulation are shown in fig. 9 and fig. 10. The temperature difference between the actual measurements and simulated results based on those measurements were on average about $1.4^{\circ} \mathrm{C}\left(2.5^{\circ} \mathrm{F}\right)$ for the same locations. The actual temperature measurements were all higher than their simulated data points. 
Based on the small but consistent difference in temperature data between the actual and simulated data points and the consistently lower temperature readings from the simulation, it is assumed that the simulations show a fair representation of the temperature and conditioned air distribution in modular3.

Unfortunately, the simulation output for both temperature and LMA distribution based on the actual performance data were not as evenly distributed as those resulting from the pre-construction simulation as shown in fig. 7 and fig. 8 above. This was primarily a result of the installed mechanical system and ductwork performing differently than originally anticipated during the design development stage. Although the actual total supply air volume $755 \mathrm{~L} / \mathrm{s}$ (1600 CFM) was consistent with the simulated data, the volume of supply air from each vent varied an average of $8.8 \mathrm{~L} / \mathrm{s}$ (18.7 CFM). With proper control of the supply air volume from each supply vent, it would be possible to achieve a more uniform LMA and temperature distribution pattern in line with the preconstruction simulation results.
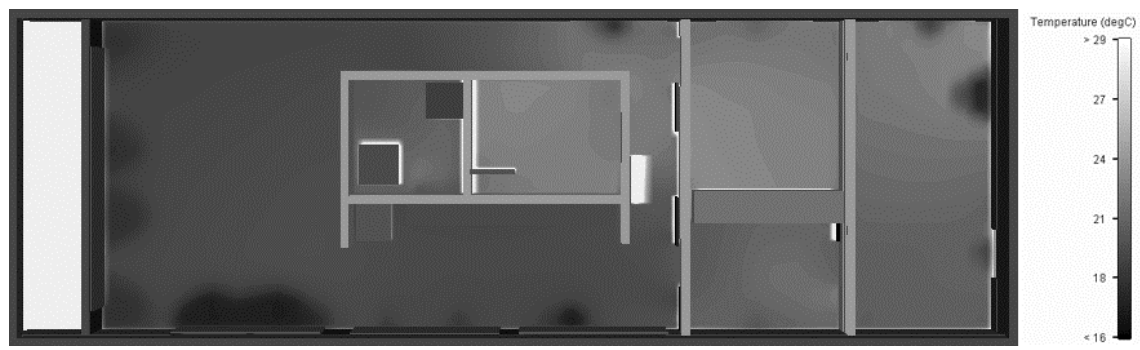

Figure 9: Temperature distribution of modular3 based on field measurements.
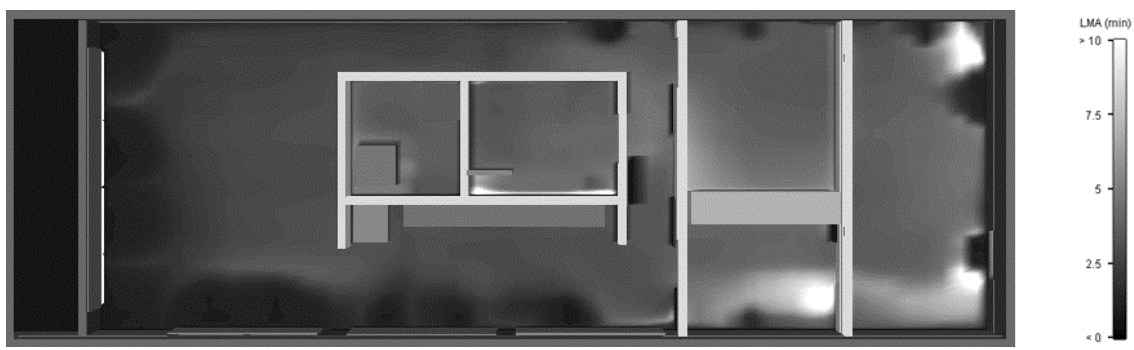

Figure 10: LMA distribution of modular3 based on field measurements.

\section{Conclusion and future directions}

Having integrated CFD, though limited in scope, into the design process of a fast paced design/build project, the future integration of CFD analysis and design development of the built environment appear to be promising areas of future research and teaching in architectural education. This experience strongly suggests that CFD can be used as an effective tool in aiding the design 
development of student design/build projects, both simple and complex in scope. Even a brief analysis of a design's environmental performance, as such was the project described here, can yield data that can potentially serve to improve the design process and final outcome. The more ongoing analysis that can be conducted during the design stage, the greater the potential positive impact on the performance of the built environment.

However, integration of CFD in the design process is not without difficulty. Because of the long learning curve associated with CFD programs, a student would not be able to effectively carry forward a performance analysis on a complex and fast paced design/build project without at least a semester of prior CFD experience and a good understanding of building environmental systems (Chang [1]). Also, because of the length of time some simulations take, depending on the scope of the project, it can be difficult to perform an analysis of multiple design scenarios within a short period of time. Therefore it would be beneficial to allow sufficient time in the design stages to study the various design schemes.

\section{References}

[1] Chang, J., Incorporating CFD into the Design Process of Architectural Education, Proceedings of the ARCC/EAAE 2006 International Conference, 2006. 